\title{
A Closed Microsurgical Technique for Anterior Vitrectomy Using a Continuous Air Infusion
}

\author{
A. M. ANSONS, P. L. ATKINSON, D. WONG. \\ Liverpool
}

\begin{abstract}
Summary
A new technique of anterior vitrectomy using a continuous air infusion is described. It has a number of advantages over conventional techniques and is recommended for the management of vitreous loss during cataract extraction. The vitreous gel is displaced posteriorly by the surface tension of an air bubble. The identification of vitreous strands is facilitated by the air/vitreous interface. Air in the anterior chamber reduces the refractive power of the cornea, providing direct visualisation of the posterior segment.
\end{abstract}

Vitreous loss complicating cataract extraction is usually managed by anterior vitrectomy, performed either through a closed section or by an open-sky technique. The vitreous may be removed using a mechanical vitrector or silicone sponges. The open-sky approach leads to hypotony and risks complications such as choroidal detachment and expulsive haemorrhage. Hypotony can be avoided by closure of the cataract section and performing the vitrectomy using an infusion. The use of a solution as the infusion can cause further vitreous prolapse. Furthermore, the identification of vitreous strands can be difficult resulting in their incomplete removal and incarceration into the section with known post-operative complications such as retinal detachment $^{1}$, chronic uveitis ${ }^{2}$ and cystoid macular oedema ${ }^{3}$.

A technique for closed anterior vitrectomy using a continuous air infusion is described which has advantages over conventional methods.

\section{Description of the technique}

In the event of vitreous loss during cataract extraction, the section is first closed using interrupted sutures and the intraocular pressure restored. No attempt is made at this stage to remove any vitreous which may be incarcerated in the section. A mechanical vitrector is then set-up with an air-line to a Grieshaber air pump* attached to the infusion port (Fig. 1). The vitrector with the air infusion is 19 guage and can be introduced through a small gap in the section. Air fills the anterior chamber and the vitreous is displaced posteriorly. The presence of an air bubble in the anterior chamber allows direct visualisation of the posterior segment through the operating microscope without the need for surface contact lenses (Fig. 2a, b), such that a deep anterior vitrectomy can be performed safely. An

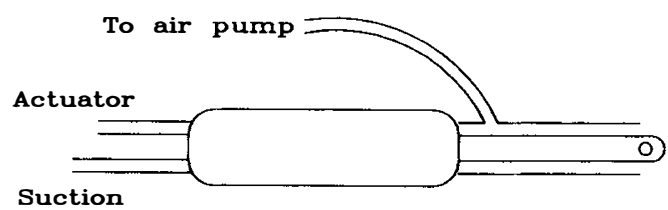

Fig. 1. Mechanical vitrector with infusion port connected to an air line. 


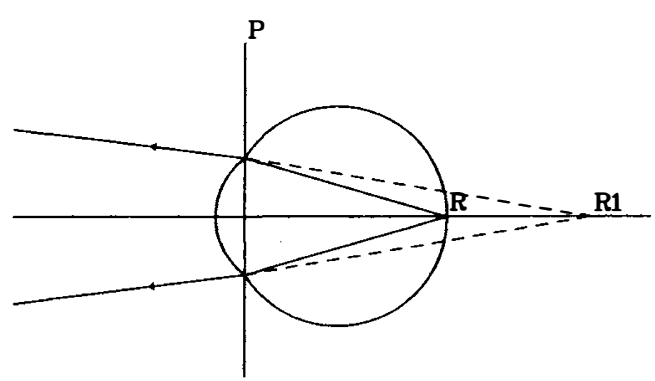

Fig. 2a. Light from the illuminated retina, $R$, emerges from the aphakic eye slightly divergent. The image R1 of the illuminated retina is formed behind the eye, beyond the focusing range of the operating microscope. ( $P=$ Principal plane $)$

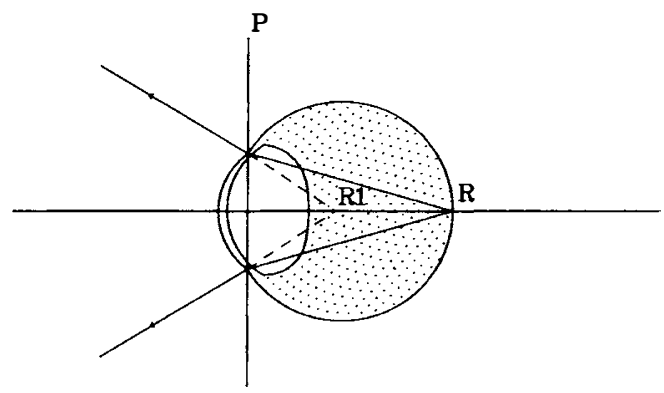

Fig 2b. Light from the illuminated retina, $R$, emerges from the air filled aphakic eye divergent. The image R1 of the illuminated retina lies within the focal range of the operating microscope. $(P=$ Principal plane $)$

adequate vitrectomy should result in air filling the anterior chamber and extending well into the posterior segment. Residual vitreous strands within the anterior chamber and incarcerated into the section are highlighted by the air/vitreous interface, and may be demonstrated by the introduction of an iris repositor. These are then removed by 'hoovering' the surface of the iris with the vitrector. Similarly, the presence of air clearly defines the posterior capsule which can usually be preserved for implantation of posterior chamber intraocular lens when appropriate. The air is then replaced with balanced salt solution, and any vitreous remaining in the section cleared using sodium hyaluronate.

\section{Discussion}

The usual management of vitreous loss complicating cataract extraction is by vitrectomy using a saline infusion. While this may be effective in maintaining the intraocular pressure it is often difficult to be certain at the end of the procedure that all the vitreous strands are removed. The main problem, is that saline has a similar refractive index to that of the vitreous making its visualisation difficult. Furthermore, fluid infusions have virtually no interfacial tension against vitreous gel and therefore cannot be expected to displace the gel posteriorly. The focal range of the microscope limits direct visualisation to the anterior one third of the vitreous cavity making deep anterior vitrectomy hazardous. It is felt that the use of air offers several advantages and these include:

1. The surface tension of the air bubble displaces vitreous gel posteriorly.

2. The air/vitreous interface facilitates identification and removal of vitreous.

3. Air in the anterior chamber reduces the refractive power of the cornea, providing direct visualisation of the posterior segment with the operating microscope (Fig. $2 \mathrm{a}, \mathrm{b})$.

4. The air-pump maintains a constant intraocular pressure throughout the procedure.

Anterior vitrectomy using a closed microsurgical technique with continuous air infusion allows safe and effective removal of displaced vitreous, reducing the risks associated with conventional methods.

\section{References}

${ }^{1}$ Shapland CD: Retinal detachment in aphakia. Trans Opthalmol Soc UK 1934, 54: 176-96.

${ }^{2}$ Ruis RS and Teeters VW: The vitreous wick syndrome: a late complication following cataract extraction. Am J Ophthalmol 1970, 70: 483-90.

${ }^{3}$ Irvine SR: A newly defined vitreous syndrome following cataract surgery. Am J Ophthaimol 1953, 36: 599 . 